\title{
Microdialysis: Opportunities and Prospects in Liver Transplantation (Review)
}

DOI: $10.17691 / \mathrm{stm} 2018.10 .3 .23$

Received/January 30, 2018

A.1. Sushkov, MD, PhD, Head of New Surgical Technologies Laboratory, Surgery and Transplantation Center; S.E. Voskanyan, MD, DSe, Deputy Chief for Surgery, Head of Surgery and Transplantation Center; K.K. Gubarev, MD, PhD, Head of Coordination Center for Human Organ and/or Tissue Donation, Surgery and Transplantation Center

State Research Center - A.I. Burnasyan Federal Medical Biophysical Center of the Federal Biological Agency, 23 Marshał Novikov St, Moscow, 123098, Russia

The assessment of donor organ quality and the initial graft function is of crucial importance, especially in liver transplantation. Recent studies have shown the feasibility of microdialysis to monitor energy metabolism in renal and liver grafts. This method is powerful and suitable to study chemical composition of interstitial fluid. It is possible to identify organ-related changes that occur early and are not reflected by changes in plasma. Currently, microdialysis is primarily applied in neurology and neurosurgery to assess the volume and severity of the brain tissue injury. The use of the technique to study the mechanisms of ischemia-reperfusion graft injury and the processes of early allograft dysfunction is a promising research trend.

The review presents the findings of both experimental and clinical trials, and discusses the advisability and prospects of microdialysis monitoring in liver transplantation.

Key words: organ transplantation; liver transplantation; microdialysis; glucose; lactate; pyruvate; glycerol.

\section{Introduction}

Currently, liver transplantation (LT) is the most effective treatment modality for patients with liver cirrhosis, acute hepatic failure, hepatocellular carcinoma, and some metabolic disorders. However, one of the key factors limiting $L T$ availability is the shortage of donor organs. A pronounced tendency of the past 10-15 years is the extended suitability criteria of donor organs (in particular, liver transplantation) for transplantation [1]. The approach is likely to be able to increase the number of transplants and decrease waiting list mortality, but it increases the risk of initial poor graft function [2]. In addition, the portion of patients operated on in a severe state according to MELD is growing [3].

The combination of a variety of risk factors is certain to result in survival decrease of grafts and recipients. In this regard, scientists worldwide are making attempts to create a reliable prognostic model of LT findings, and based on the model to develop an optimal algorithm of donor organs allocation. Generally, such researches are post-hoc analyses of findings as a part of certain transplantation programs and multi-center or register studies. Such events as recipient death and graft failure are used as end points. The list of potential predictors of failure includes a full range of characteristics of a donor and a transplantation candidate.

Another, not least important task in LT is to establish unified and universal diagnostic criteria for such conditions as early allograft dysfunction (EAD) and primary non-function (PNF) graft. Timely and accurate EAD and PNF diagnosis is essential to choose treatment modality and make a decision on retransplantation. The existing EAD criteria in most cases are boundary values of one or several laboratory parameters: aspartate- or alanine aminotransferase (AST and ALT), bilirubin, prothrombin time, prothrombin ratio, international normalized ratio (INR) in combination with clinical signs (or without them): encephalopathy, bile production, demand for fresh frozen plasma infusion. A follow up and a collection of laboratory samples within 2-7 days after transplantation are needed to diagnose EAD [4].

According to current ideas, PNF is an excess and irreversible manifestation of early dysfunction, and determined as EAD, which resulted in recipient's death or retransplantation. According to Organ Procurement and Transplantation Network (OPTN) and United Network for Organ Sharing (UNOS) criteria [5], PNF can be diagnosed if AST is over $3000 \mathrm{U} / \mathrm{L}$, or at least one of the following indices determined in blood sample within 1-7 days after transplantation:

INR $\geq 2.5$;

acidosis (arterial blood $\mathrm{pH}$ is $\leq 7.30$ and/or venous blood $\mathrm{pH}$ is $\leq 7.25$ );

lactate $\geq 4.0 \mu \mathrm{mol} / \mathrm{L}$.

An approach involving the functionality test of a

Corresponding author: Alexander I. Sushkov, e-mail: sushkov.transpl@gmail.com 
transplanted liver based on the findings of standard laboratory tests is appropriate, since it does not require any additional equipment and consumables, and can be used in any transplant center. On the other hand, relatively low sensitivity and specificity of a particular parameter require their combined analysis. Multidirectional tendencies of changing a set of laboratory tests, as well as possible data mismatch to a clinical presentation determine the necessity to prolong a follow up period that delays establishing a diagnosis, and in case of PNF — making a decision on retransplantation. Moreover, an altered composition of peripheral blood having an impact on graft functions proceeds with certain time delay that can be of substantial clinical relevance. Renal replacement therapy, albumin dialysis, fresh frozen plasma, and coagulation factor concentrate in patients with severe graft dysfunction and coagulopathy is likely to enable to correct effectively hemo- and homeostasis disorders, however, it can create a false impression of liver functional recovery.

Thus, the problem of a rapid and objective assessment of an initial graft function has become more relevant when being used for transplating extendedcriteria donor organs.

Currently, there have been developed and approved in clinics several methods for direct assessment of liver functions including LT cases: maximum liver function capacity according to ${ }^{13} \mathrm{C}$-metacetine clearance (LiMAx test) $[6,7]$, liver function and perfusion measurement according to indocyanine green clearance (LIMON test) $[8,9]$, interstitial microdialysis [10]. The first two methods are based on non-invasive concentration measurement of the substances specifically metabolized $\left({ }^{13} \mathrm{C}\right.$-metacetine) or secreted (indocyanine green) by the liver. Microdialysis is more universal, since it enables to measure the concentration of any substances in the interstitial space of the tissue under study.

\section{Method principle}

Interstitial microdialysis is in vivo concentration measurement technology of substances dissolved in interstitial space, the technique being based on the phenomenon of passive diffusion of substances through a semipermeable membrane by a concentration gradient.

The method prototype was first represented by Bito et al. [11] in 1966 to determine the concentrations of amino acids and electrolytes in dog cerebrospinal fluid, brain tissue, and blood. In 1972, Delgado et al. [12] suggested a thin glass catheter for interstitial fluid sample acquisition. Fifteen years later, Lönnroth et al. [13] implanted a sample catheter in subcutaneous fat of healthy volunteers and demonstrated the capabilities of measuring extracellular glucose concentration.

Further development of the technology, accumulation, and analysis of experimental and clinical data were related to the first industrial production of microdialysis catheters and compact analyzers of extracellular fluid microsamples. Since 1990s microdialysis has been extensively used in neurosurgery and neurology to monitor biochemical indexes in the brain tissue.

Polyurethane microdialysis catheter, about $1 \mathrm{~mm}$ in diameter, has two lumens concentrically located; the outer surface of its terminal part is from 1 to $3 \mathrm{~cm}$ and made from the semipermeable membrane (see the Figure). When implanted in the tissue under study through an inner catheter lumen using a micropump at the rate of $0.1-5.0 \mu \mathrm{l} / \mathrm{min}$ (usually, $0.3 \mu \mathrm{l} / \mathrm{min}$ ), the infusion of isotonic interstitial fluid saline is started. The perfusion fluid composition can be different, however, it is optimal to use a special standard solution, maximally close to interstitial fluid in ion composition: $\mathrm{Na}^{+}$is $147 \mu \mathrm{mol} / \mathrm{L}, \mathrm{K}^{+}-4.0 \mu \mathrm{mol} / \mathrm{L}, \mathrm{Ca}^{2+}-2.3 \mu \mathrm{mol} / \mathrm{L}, \mathrm{Cl}^{-}-$ $156 \mu \mathrm{mol} / \mathrm{L}, \mathrm{pH} 6.0$, osmolality $-290 \mathrm{mOsm} / \mathrm{L}$. When perfusion fluid reaches the semipermeable membrane, with concentration increase passive substance transport from interstitial fluid to a catheter cavity begins, and therefore, the composition of perfusion fluid changes. The obtained solution is continuously removed through the second catheter lumen at the same rate and collected in a microvial. The membrane permeability is determined by the size of its pores - most frequently, in clinical practice we use the catheters able to permeate the substances with molecular weight of $20 \mathrm{kDa}$ (glucose, lactate, pyruvate, glycerol, etc.). If the size of pores increases to $100 \mathrm{kDa}$, it is possible to determine interstitial concentration of small protein molecules, e.g. cytokines. Constant motion of perfusion fluid enables to maintain transmembrane concentration gradient and continuous transport of substances from interstitial space to a catheter cavity. It must be emphasized that some time is needed to equalize completely the concentrations on either side of the membrane, but due to the fact that perfusion fluid is constantly moving, the concentration of substances in the resultant dialysate is slightly lower than in the tissue under study. In a membrane of standard length $(10 \mathrm{~mm})$ the perfusion rate $(0.3 \mu \mathrm{l} / \mathrm{min})$ is about $70 \%$ from the reference one [14].

A real concentration of a substance in tissue can be found by several calculation methods, however, generally, recalculation is not made, since concentration dynamics is of concern rather than its absolute value.

Outflowing dialysate is collected in a microvial, which is changed by next one when it is full. From 20 to $60 \mathrm{~min}$ are required to get a sufficient dialysate volume. The concentration of basic markers of energy metabolism can be determined using a portable analyzer immediately after sample acquisition. Dialysate transit time from the membrane to a test tube is about $17 \mathrm{~min}$. It can be very important when carrying out experimental studies if there should be an exact timing correlation between any procedure and the change of interstitial fluid composition. In clinical practice such delay is 


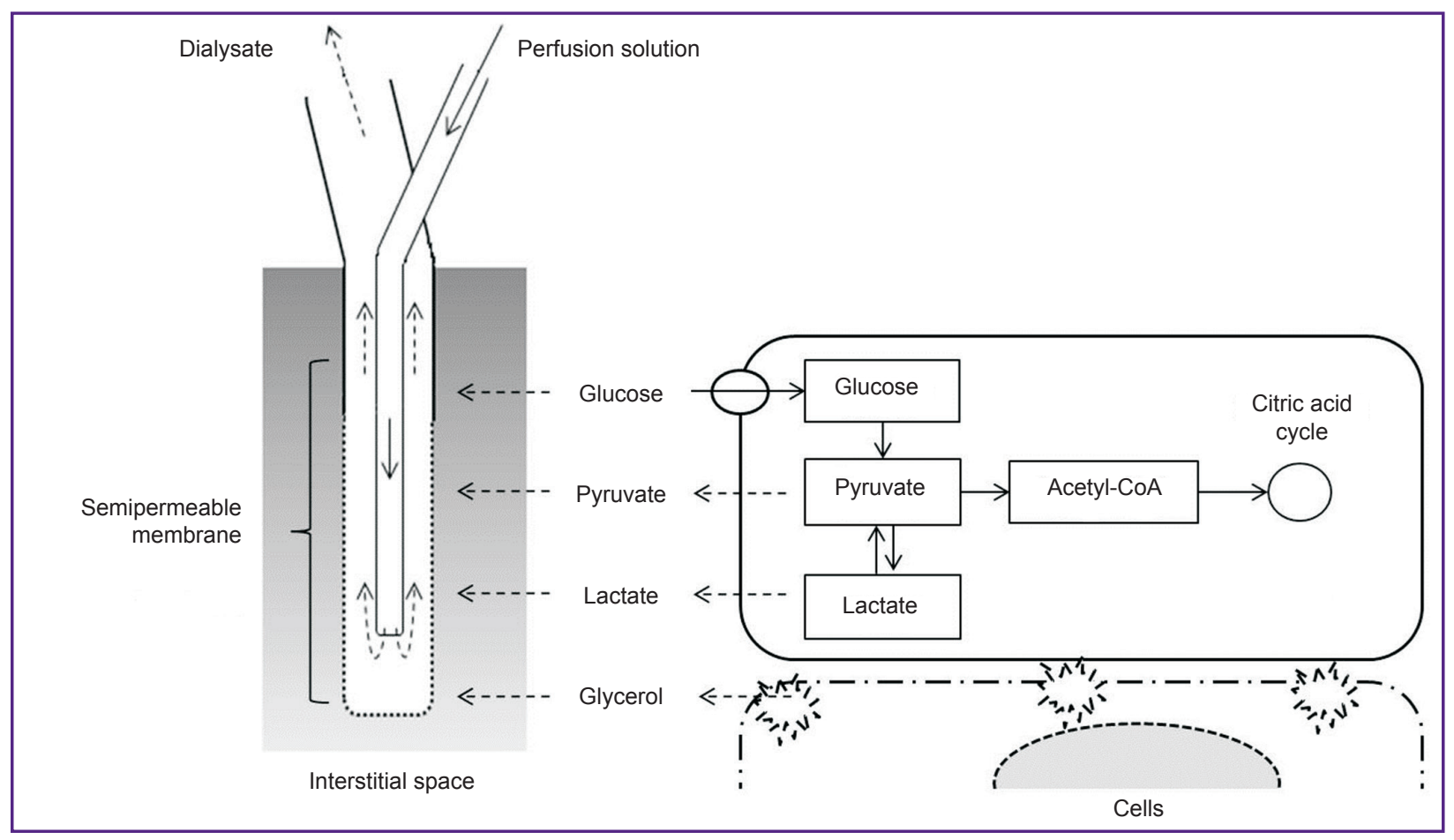

A microdialysis catheter and the transport of the substances under study

neglected, since measurements are performed no more than once an hour.

\section{The significance of changing glucose concentration, its metabolites and glycerol in graft tissues}

The ability of hepatocytes to synthesize a sufficient amount of adenosine triphosphate (ATP) is one of the essential functional indices of a transplanted liver [15]. Generally, in aerobic glycolysis, glucose is degraded to pyruvate, which serves as a substrate for oxidative phosphorylation and ATP production; it is possible only in adequate tissue oxygenation and the normal work of mitochondria. In impaired oxygen delivery or mitochondrial damage, glucose metabolism chooses the anaerobic way with lactate synthesized from pyruvate and less ATP produced. In ischemic damage of the organ, there is a reduced concentration of glucose and pyruvate, and at the same time - an increased lactate level. An interstitial glucose concentration depends mainly on regional blood supply, however, there can be low glucose in no misperfusion as well, e.g. in high metabolism and hyperglycolysis. When determining the lactate and pyruvate concentrations, it is necessary to take into consideration glucose level, since their indices can be related to physiological changes of glucose metabolic rate or its increased delivery to cells rather than to ischemia. When interpreting the changes, it is customary to use coefficients showing the relations between the concentrations of lactate and pyruvate (lactate-pyruvate ratio (LPR)), and lactate and glucose (lactate-glucose ratio (LGR)) rather than use absolute values. The increase of the coefficients suggests the insufficiency of aerobic glycolysis due to mitochondrial ischemia or dysfunction in normal oxygen delivery [1631].

Ischemic and reperfusion injuries, as well as immune destruction, which inevitably accompany any transplantation, result in the death of some cells of a donor organ accompanied by the degradation of cell membrane phospholipids and glycerol formation. Glycerol concentration in interstitial space can also be measured by microdialysis, and the concentration increase will show cytolysis degree. However, there can be a nonspecific increase of the marker due to lipolysis in response to a surgical injury and adrenaline rush, or when taking glycerol-containing medications.

It must be emphasized that the dynamics of measurable parameters is of diagnostic value and clinical relevance but not their absolute value at some particular point of time. This is precisely why microdialysis should be considered as a monitoring of a graft condition rather than an additional test to assess the transplanted organ functions, in particular, the transplanted liver.

\section{The findings of experimental and clinical studies on using microdialysis in organ transplantation}

The search for the findings of the studies devoted to microdialysis application to assess the viability and functions of transplanted organs in experiments and 
clinical practice was made in an open database of medical and biological publications PubMed (http://www. ncbi.nlm.nih.gov/pubmed/) using a search query "Organ Transplantation" [Mesh] AND "Microdialysis" [Mesh]. As of January 1, 2018, there have been found 35 works published from 1995 to 2017, among them 28 original articles met the review subject.

Regardless of the fact that microdialysis technically can be used to study the processes proceeding in any organ, all works appeared to be concerned with either the liver or the kidney study, it is likely to be related to increased necessity for the transplantations of these organs and the number of liver and kidney transplantations performed. The Table presents the distribution of works by their type and subject of research

Primarily, experimental studies are carried out on kidney ischemia-reperfusion and/or transplantation models, it is likely to be due to relative technical simplicity. The majority of clinical studies concern with liver transplantation, when an objective assessment of an initial graft function is of primary importance and, in the meantime, is difficult using standard diagnostic tests.

There are 5 European centers, the worldwide transplantation leaders; they have 21 from 28 publications: 22];

Huddinge University Hospital, Sweden [18, 19, 21,

Queen Elizabeth Hospital, Great Britain [23-27];

Aarhus University Hospital, Denmark [33-37];

University of Heidelberg, Germany [38-41];

Oslo University Hospital, Norway [29-31].

Kidney transplantation. Generally, experimental studies on a transplanted kidney model aim at revealing the relations between the warm ischemia time and cold ischemia time and glucose interstitial metabolism both: at preservation and after reperfusion $[32,34,36$, $39,40]$. No blood flow in an organ is typically due to depletion of glucose and pyruvate supplies in addition to a growing concentration of lactate and glycerol. Under warm ischemia the rate of concentration change of these substances is significantly higher than in hypothermia. After an adequate blood flow is recovered, all indices normalize quickly, slow glycerol level decrease being the characteristic for severe and, probably, continuing ischemic and reperfusion injury (IRI).

Another no less important direction of experimental works is the study of microdialysis capabilities used for early diagnosis of graft thrombosis [33, 35, 37, 38]. All researches demonstrate characteristic concentration alterations of glucose and its metabolites to be seen just $30 \mathrm{~min}$ after partial or complete renal blood flow reduction. Amdisen et al. [37] have shown the advantages of microdialysis compared to the Doppler ultrasound flow sensors to diagnose misperfusion along the graft artery and vein.

Fonouni et al. [41] have discussed an increased concentration of interstitial lactate and LPR growth as a
The studies using microdialysis in transplantation

\begin{tabular}{lcc}
\hline \multicolumn{1}{c}{ Organs } & Experimental study & Clinical study \\
Liver & $n=6[16-20,22]$ & $n=10[21,23-31]$ \\
Kidney & $n=11[32-42]$ & $n=1[43]$ \\
\hline
\end{tabular}

Note: $\mathrm{n}$ - number of studies; literature references are given in square brackets.

possible marker of acute rejection of a kidney transplant. From our point of view, the changes are secondary, nonspecific, and due to impaired microcirculation resulted from inflammatory edema of a graft, and therefore, cannot be considered as a reliable diagnostic technique of organ rejection. It may happen that the use of microdialysis catheters with large-size pores and the concentration measurement of interleukins, chemokines, and other signal molecules will be of more help to diagnose rejection.

A single clinical study devoted to the analysis of interstitial glucose metabolism monitoring to assess IRI severity of kidney graft was carried out in Russia by the researchers of Sklifosovsky Research Institute of Emergency Care and V.A. Negovsky Research Institute of General Reanimatology [43]. The authors showed that the dynamics of lactate, glycerol, and LPR can be considered as a factor determining an initial graft stage. Despite an absolute value of the findings, the prospect for clinical use of the technique in kidney transplantation is ambiguous, since a postoperative function of a transplanted organ is easily estimated by urine, creatinine, potassium levels, blood acid-base balance, and a delayed graft function poses no hazard to life in case of duly started renal replacement therapy. On the other hand, a study carried out at a donor's stage and during preservation will enable to obtain clinically essential data on the organ quality and predict a critical time for cold ischemia, reasonably refuse the transplantation of a donor's organ with high risk of PNF.

Liver transplantation. First researches devoted to the study of energy metabolism in the liver in its preservation for further transplantation were performed on rats in the mid 1990s. One study compared the efficiency of preservative solutions of Wisconsin University (UW) and Euro-Collins [16], and another - the solutions with different contents of $\mathrm{K}^{+}$ions [17].

We should make special reference to an experimental work by Nowak et al. [18], they first described the alteration regularities of interstitial concentrations of glucose, lactate, pyruvate, and glycerol in the liver at a donor's stage, during cold preservation, within transplantation and in the immediate postoperative period $(7 \mathrm{~h})$. The authors remarked that immediately after liver perfusion in the donor's body by a cold UW solution, there was a sharp decrease in pyruvate concentration and the growth of glucose, lactate, and glycerol. During cold preservation that lasted $14-15 \mathrm{~h}$, glucose and 
glycerol concentrations kept growing, while a lactate level showed no significant variations, and pyruvate was nearly zero. When forming anastomoses, and a graft is warmed by surrounding tissues, the level of glucose, lactate, and glycerol was increasing for 40-60 min after blood started circulating in the portal vein, and then after arterial blood supply recovered, their level began decreasing, and by the end of the experiment it was equal to initial (normal) values. Within the procedure, pyruvate concentration increased reaching its maximum $2 \mathrm{~h}$ after reperfusion, on the average, and then returned to its normal value. Thus, intraoperative warm ischemia and reperfusion are accompanied by the most marked graft damage, while the phenomenon of increased glucose concentration during cold preservation is specific for the liver and related to glycogenolysis, glycogen being released from damaged hepatocytes.

Some years later, the same research team showed in experiment that increased duration of cold storage of liver transplant results in glycogenolysis enhancement, the delayed recovery of aerobic glucose metabolism, and an increased period of anaerobic glycolysis after reperfusion $[19,22]$.

Meaningful results were obtained in experiment by Nagayama et al. [20] from Sapporo Medical University (Japan). The authors stated that hypoxanthine level in the liver tissue of non-heart beating donor determined by microdialysis immediately before the organ retrieval procurement was related to a 7-day survival of laboratory animals. That was an interstitial hypoxanthine concentration that highly correlated with the intensity of histological signs of graft damage and lethality than the primary warm ischemia time. The introduction of the approach into clinical practice appears to enable to objectively determine a tolerance reserve for a certain graft to ischemic damage, and predict an immediate outcome and selectively use when transplanting the organs of non-heart beating donors, without increasing PNF risk; however, no such reports were found in literature.

Most clinical studies aimed at determining IRI severity of a hepatic graft and assessing its initial function. In 2002 Nowak et al. [21] published the work confirming the regularities, which had been found experimentally before [18], however, interstitial glucose and its metabolites were measured only after transplantation - within 3 days after surgery. Analyzing the case when on day 2 after transplantation congestive heart failure developed in a patient due to tamponade, the authors cogently demonstrated that microdialysis can help diagnosing impaired perfusion of a transplanted organ: the significant growth of lactate in the liver was recorded $3 \mathrm{~h}$ earlier than similar changes in the peripheral blood.

The studies carried out in 2005-2008 [23-27] by a research team from Queen Elizabeth Hospital (Birmingham, Great Britain) are of the utmost interest. The first published work [23] studied the observation data of 18 adult patients after deceased donor full liver transplantation. Microdialysis samples were collected from the time of the graft reperfusion and within $48 \mathrm{~h}$. In addition to glucose, lactate, pyruvate and glycerol level, they measured interstitial concentrations of alanine, arginine, citrulline, gamma-aminobutyric acid, glutamate, glutamine, glycine, and taurine. All grafts functioned adequately that made it possible for the authors to state the typical (normal) nature of interstitial concentration change of glucose, its metabolites and glycerol in an immediate post-transplantation period.

Further, in a series of 15 sequentially performed liver transplantations [24], microdialysis samples were collected from the time of the organ retrieval till the end of the second post-transplantation day. AST values over $2000 \mathrm{U} / \mathrm{L} 24 \mathrm{~h}$ after the surgery was taken as a diagnostic criterion of a significant IRI. Interstitial lactate in IRI patients $(n=6)$ was over $6 \mu \mathrm{mol} / \mathrm{L}$ even at a donor's stage, and by the end of cold ischemia (during graft preparation for implantation) it exceeded $15 \mu \mathrm{mol} / \mathrm{L}$ that was significantly higher than in patients without IRI $(n=9)$. However, no significant differences between these groups of patients were found in glucose, pyruvate and glycerol concentrations.

In their following works, the authors studied the dynamics of interstitial arginine concentration as a central link in urea and nitric oxide metabolism in the liver [25], as well as other amino acids [26] at all transplantation stages and within an immediate postoperative period. Primarily, the findings and the revealed regularities are fundamental and demonstrate the capabilities of microdialysis for further study of metabolism pathophysiology in a liver graft, if its initial function was compromised. There has been proved the relation between complement system activation (C4d component fixation on the membrane of hepatocytes), interstitial lactate-acidosis and an EAD [27].

Concurrently, in Oslo University Hospital (Norway) Waelgaard et al. [28] carried out a similar research, which included 20 liver recipients. Within seven postoperative days, in graft tissue, in addition to standard indices of energy metabolism, they recorded the concentrations of cytokines: interleukin-6 (IL-6), interleukin-8 (IL-8), monocyte chemoattractant protein-1 (MCP-1) induced by interferon gamma-induced protein-10 (IP-10), and C5a-complement component. 15-fold growth of IP-10 concentration (from 200 to $3000 \mathrm{pg} / \mathrm{ml}$ ) in a stable level of other cytokines was typical for all patients with normal graft functioning. Two recipients with acute rejection were found to have 10-15-fold increase of interstitial concentration of $\mathrm{IL}-8$ and $\mathrm{C} 5 \mathrm{a}$ compared to the initial concentrations, the concentrations starting growing 2-4 days earlier than AST and ALT growth in peripheral blood. Moreover, an early postoperative period in one patient was complicated by the graft artery thrombosis and acute rejection. The patient was recorded to have a rapid growth of interstitial lactate and increased IL-8 and C5a concentrations.

The investigation involving most recipients was also 
performed in Norway [29]. Interstitial concentrations of glucose, lactate, pyruvate, and glycerol were measured, on average, within 10 days after transplantation. 12 patients developed acute rejection confirmed by biopsy. Ischemic graft damage was diagnosed in 9 cases, the damage being determined as occlusion/ stenosis of vessels or parenchymal infarction detected by ultrasound and/or computed tomography. A control group included 39 recipients with an uncomplicated postoperative period. An interstitial lactate level in rejection and ischemia was significantly higher than in the control group. The highest pyruvate concentrations were found in rejection, while LPR and glycerol growth was characteristic for ischemic damage. The authors reported that interstitial concentrations of glucose metabolites and glycerol have $100 \%$ sensitivity and over $90 \%$ specificity in ischemic damage diagnosis, if their characteristic alterations are recorded in two sequential samples taken at one-hour intervals. Persistent decrease in pyruvate level within $6 \mathrm{~h}$ suggests graft rejection, sensitivity, and specificity values being $80 \%$. In all rejection cases, on the average, microdialysis samples changed 4 days earlier than the rise of aminotransferase and bilirubin levels in the peripheral blood [29].

The same research group measured interstitial concentrations of C5a-complement component, chemokines CXCL8 and CXCL10, IL-1, IL-6, IL10 receptor antagonist, macrophage inflammatory protein $1 \beta$ in health and in complications [30]. The markers CXCL10 and C5a showed the highest value, respectively, when diagnosing rejection and ischemic damage. However, in the before mentioned work by Waelgaard et al. [28] an increased C5a level was typical for rejection rather than for ischemia.

To sum up, there should be mentioned the study by Haugaa et al. [31], which concerns with the use of microdialysis in children recipients (20 patients, mean age -1.9 years, mean weight $-9.1 \mathrm{~kg}$ ). Due to the fact that LT in children is related to the higher risk and frequency of vascular complications, early and accurate diagnosis of impaired graft perfusion is of great significance. The study convincingly demonstrates that graft ischemia in microdialysis monitoring can be diagnosed without delay, with $100 \%$ sensitivity and $86 \%$ specificity, and all the determinate variations of interstitial concentrations of glucose, lactate, pyruvate, and glycerol found in adults are true for children population.

\section{Conclusion}

The analysis of experimental and clinical findings of using microdialysis in organ transplantation showed the technique is likely to enable to obtain objective data on a graft functional status, and the measured parameters are sensitive and specific markers of ischemic damage. The analysis of cytokines in interstitial fluid seems to be a promising trend in rejection diagnosis; however, the findings so far are insufficient to develop a reliable diagnostic technology. The relevance of further researches in this field and the search for regularities in interstitial biomarkers changing in health and disease is undisputed.

A relatively small amount of publications and the researches performed just in several transplant centers is hard to explain by method unavailability or high cost of consumables, since in other fields of experimental and clinical medicine, especially in neurology and neurosurgery, microdialysis is used very extensively. Probably, the situation is due to certain conservative views and historically developed practice to consider a histological study to be a gold standard in diagnosis when estimating donor's organ qualities, as well as establishing the reasons for graft dysfunction. Currently, morphological methods (light microscopy, immunohistochemistry, electron microscopy) are likely to give a clinician a great deal of evidence that frequently plays a key role in management preference. However, unlike other conditions, the transplantation of any organ is accompanied by maximum variation of function that is determined by numerous interrelating time-varying factors. Frequently, the variation of an organ function is significantly ahead of a morphological picture or accompanied by its nonspecific alterations, therefore, the methods of dynamic monitoring of a graft status are of primary importance.

The subjects of the latest discoveries and developments in organ donation give evidence of an occurring change of an ideological approach if previously the main objective was to find donor organs matching a number of specified criteria, now a rehabilitation concept is of current interest, i.e. improvement of qualities of organs initially inadequate for transplantation, and their transplantation with a predictable initial function and a favorable outcome. A key role in the process is assigned to the formation of new perfusion systems, which are certain to have a collection of diagnostic modules. An analyzer of an interstitial fluid composition of a donor's organ can be one of such modules.

The analysis of current trends and relevant issues of clinical LT in the practice of foreign and Russian centers has shown that one of promising directions in research activity are the assessment and monitoring of an initial function of a transplanted organ.

Study Funding. The study was supported by Russian Science Foundation grant (Project No.17-75-10010).

Conflicts of interest. The authors declare no conflicts of interest related to the present study.

\section{References}

1. Jadlowiec C.C., Taner T. Liver transplantation: current status and challenges. World J Gastroenterol 2016; 22(18): 4438-4445, https://doi.org/10.3748/wjg.v22.i18.4438.

2. Nemes B., Gámán G., Polak W.G., Gelley F., Hara T., 
Ono S., Baimakhanov Z., Piros L., Eguchi S. Extended-criteria donors in liver transplantation. Part II: reviewing the impact of extended-criteria donors on the complications and outcomes of liver transplantation. Expert Rev Gastroenterol Hepatol 2016; 10(7): 841-859, https://doi.org/10.1586/17474124.2016. 1149062.

3. Kwong A.J., Fix O.K. Update on the management of the liver transplant patient. Curr Opin Gastroenterol 2015; 31(3): 224-232, https://doi.org/10.1097/mog.0000000000000173.

4. Chen X.B., Xu M.Q. Primary graft dysfunction after liver transplantation. Hepatobiliary Pancreat Dis Int 2014; 13(2): 125-137, https://doi.org/10.1016/s1499-3872(14)60023-0.

5. United Network For Organ Sharing. United Network for Organ Sharing Liver Disease Severity Score Committee. 2014. URL: www.unos.org.

6. Stockmann M., Lock J.F., Malinowski M., Seehofer D., Puhl G., Pratschke J., Neuhaus P. How to define initial poor graft function after liver transplantation? - a new functional definition by the LiMAx test. Transpl Int 2010; 23(10): 102310102332, https://doi.org/10.1111/j.1432-2277.2010.01089.x.

7. Lock J.F., Schwabauer E., Martus P., Videv N., Pratschke J., Malinowski M., Neuhaus P., Stockmann M. Early diagnosis of primary nonfunction and indication for reoperation after liver transplantation. Liver Transp/ 2010; 16(2): 172-180, https://doi.org/10.1002/lt.21973.

8. Levesque E., Saliba F., Benhamida S., Ichaï P., Azoulay D., Adam R., Castaing D., Samuel D. Plasma disappearance rate of indocyanine green: a tool to evaluate early graft outcome after liver transplantation. Liver Transpl 2009; 15(10): 1358-1364, https://doi.org/10.1002/lt.21805.

9. De Gasperi A., Mazza E., Prosperi M. Indocyanine green kinetics to assess liver function: ready for a clinical dynamic assessment in major liver surgery? World $\mathrm{J}$ Hepatol 2016; 8(7): 355-367, https://doi.org/10.4254/wjh.v8.i7.355.

10. Ramsay M. Role of microdialysis catheters in clinical decision making: bench to bedside? Liver Transp/ 2013; 19(3): 243-235, https://doi.org/10.1002/lt.23602.

11. Bito L., Davson H., Levin E., Murray M., Snider N. The concentrations of free amino acids and other electrolytes in cerebrospinal fluid, in vivo dialysate of brain, and blood plasma of the dog. J Neurochem 1966; 13(11): 1057-1067, https://doi. org/10.1111/j.1471-4159.1966.tb04265.x.

12. Delgado J.M., DeFeudis F.V., Roth R.H., Ryugo D.K., Mitruka B.M. Dialytrode for long term intracerebral perfusion in awake monkeys. Arch Int Pharmacodyn Ther 1972; 198(1): 9-21.

13. Lönnroth P., Jansson P.A., Smith U. A microdialysis method allowing characterization of intercellular water space in humans. Am J Physiol 1987; 253(2): E228-E231, https://doi. org/10.1152/ajpendo.1987.253.2.e228.

14. Hutchinson P.J., O'Connell M.T., al-Rawi P.G., KettWhite R., Gupta A.K., Kirkpatrick P.J., Pickard J.D. Clinical cerebral microdialysis - determining the true extracellular concentration. Acta Neurochir Suppl 2002; 81: 359-362, https://doi.org/10.1007/978-3-7091-6738-0_91.

15. Bruinsma B.G., Avruch J.H., Sridharan G.V., Weeder P.D., Jacobs M.L., Crisalli K., Amundsen B., Porte R.J., Markmann J.F., Uygun K., Yeh H. Peritransplant energy changes and their correlation to outcome after human liver transplantation. Transplantation 2017; 101(7): 1637-1644, https://doi.org/10.1097/tp.0000000000001699.

16. Wahlberg J., Eklund T., Hillered L. Comparison of energy metabolism in rat liver grafts during preservation in
University of Wisconsin or Euro-Collins solutions. Transplant Proc 1995; 27(1): 721-723.

17. Tian Yh., Fukuda C., Schilling M.K. Interstitial accumulation of $\mathrm{Na}+$ and $\mathrm{K}+$ during flush-out and cold storage of rat livers: implications for graft survival. Hepatology 1998; 28(5): 1327-1331, https://doi.org/10.1002/hep.510280522.

18. Nowak G., Ungerstedt J., Wernerman J., Ungerstedt U., Ericzon B.G. Metabolic changes in the liver graft monitored continuously with microdialysis during liver transplantation in a pig model. Liver Transpl 2002; 8(5): 424-432, https://doi. org/10.1053/jts.2002.32943.

19. Gillispie A., Rooyackers O., Wernerman J., Nowak G. Effect of extended cold ischemia time on glucose metabolism in liver grafts: experimental study in pigs. J Hepatobiliary Pancreat Surg 2007; 14(2): 183-188, https://doi.org/10.1007/ s00534-006-1127-z.

20. Nagayama M., Katsuramaki T., Kimura H., Isobe M., Meguro M., Matsuno T., Nui A., Hirata K. Prediction of graft viability from non-heart-beating donor pigs using hepatic microdialysate hypoxanthine levels. J Surg Res 2002; 107(2) 210-218, https://doi.org/10.1006/jsre.2002.6514.

21. Nowak G., Ungerstedt J., Wernerman J., Ungerstedt U., Ericzon B.G. Clinical experience in continuous graft monitoring with microdialysis early after liver transplantation. $\mathrm{Br} J$ Surg 2002; 89(9): 1169-1175, https://doi.org/10.1046/j.13652168.2002.02187.x.

22. Nowak G., Ungerstedt J., Wernerson A., Ungerstedt U., Ericzon B.G. Hepatic cell membrane damage during cold preservation sensitizes liver grafts to rewarming injury. J Hepatobiliary Pancreat Surg 2003; 10(3): 200-205, https:// doi.org/10.1007/s00534-002-0760-4.

23. Silva M.A., Richards D.A., Bramhall S.R., Adams D.H., Mirza D.F., Murphy N. A study of the metabolites of ischemiareperfusion injury and selected amino acids in the liver using microdialysis during transplantation. Transplantation 2005; 79(7): 828-835, https://doi.org/10.1097/01.tp.0000153156. 38617.97.

24. Silva M.A., Murphy N., Richards D.A., Wigmore S.J., Bramhall S.R., Buckels J.A., Adams D.H., Mirza D.F. Interstitial lactic acidosis in the graft during organ harvest, cold storage, and reperfusion of human liver allografts predicts subsequent ischemia reperfusion injury. Transplantation 2006; 82(2): 227233, https://doi.org/10.1097/01.tp.0000226234.76036.c1.

25. Silva M.A., Mirza D.F., Buckels J.A., Bramhall S.R., Mayer D., Wigmore S.J., Murphy N., Richards D.A. Arginine and urea metabolism in the liver graft: a study using microdialysis in human orthotopic liver transplantation. Transplantation 2006; 82(10): 1304-1311, https://doi. org/10.1097/01.tp.0000241099.93794.d6.

26. Richards D.A., Silva M.A., Murphy N., Wigmore S.J., Mirza D.F. Extracellular amino acid levels in the human liver during transplantation: a microdialysis study from donor to recipient. Amino Acids 2007; 33(3): 429-437, https://doi. org/10.1007/s00726-006-0480-1.

27. Silva M.A., Mirza D.F., Murphy N., Richards D.A., Reynolds G.M., Wigmore S.J., Neil D.A. Intrahepatic complement activation, sinusoidal endothelial injury, and lactic acidosis are associated with initial poor function of the liver after transplantation. Transplantation 2008; 85(5): 718-725, https://doi.org/10.1097/tp.0b013e3181663366.

28. Waelgaard L., Thorgersen E.B., Line P.D., Foss A. Mollnes T.E., Tønnessen T.I. Microdialysis monitoring of liver grafts by metabolic parameters, cytokine production, and 
complement activation. Transplantation 2008; 86(8): 10961103, https://doi.org/10.1097/tp.0b013e31818775ca.

29. Haugaa H., Thorgersen E.B., Pharo A., Boberg K.M., Foss A., Line P.D., Sanengen T., Almaas R., Grindheim G., Pischke S.E., Mollnes T.E., Tønnessen T.I. Early bedside detection of ischemia and rejection in liver transplants by microdialysis. Liver Transp/ 2012; 18(7): 839-849, https://doi. org/10.1002/lt.23425.

30. Haugaa H., Thorgersen E.B., Pharo A., Boberg K.M., Foss A., Line P.D., Sanengen T., Almaas R., Grindheim G., Waelgaard L., Pischke S.E., Mollnes T.E., Inge Tønnessen T. Inflammatory markers sampled by microdialysis catheters distinguish rejection from ischemia in liver grafts. Liver Transpl 2012; 18(12): 1421-1429, https://doi.org/10.1002/lt.23503.

31. Haugaa H., Almaas R., Thorgersen E.B., Foss A., Line P.D., Sanengen T., Bergmann G.B., Ohlin P., Waelgaard L., Grindheim G., Pischke S.E., Mollnes T.E., Tønnessen T.I. Clinical experience with microdialysis catheters in pediatric liver transplants. Liver Transpl 2013; 19(3): 305314, https://doi.org/10.1002/lt.23578.

32. Baicu S.C., Simmons P.M., Campbell L.H., Taylor M.J., Brockbank K.G. Interstitial fluid analysis for assessment of organ function. Clin Transplant 2004; 18(Suppl 12): 16-21, https://doi.org/10.1111/j.1399-0012.2004.00212.

33. Keller A.K., Jorgensen T.M., Olsen L.H., Stolle L.B. Detection of local metabolic changes after progressive and stepwise reduction of renal blood flow in pigs. Transplant Proc 2009; 41(1): 44-48, https://doi.org/10.1016/j. transproceed.2008.10.089.

34. Keller A.K., Jorgensen T.M., Ravlo K., Nielsen T.K., Olsen L.H., Stolle L.B. Microdialysis for detection of renal ischemia after experimental renal transplantation. $J$ Urol 2009; 182(4 Suppl): 1854-1859, https://doi.org/10.1016/j. juro.2009.03.015.

35. Keller A.K., Jorgensen T.M., Vittrup D.M., Kjerkegaard U.K., Jespersen B., Krag S.R., Bibby B.M., Stolle L.B. Fast detection of renal ischemia in transplanted kidneys with delayed graft function-an experimental study. Transplantation 2013; 95(2): 275-279, https://doi.org/10.1097/ tp.0b013e318276a1c8.

36. Keller A.K., Kierulf-Lassen C., Møldrup U., Bibby B.M., Jespersen $B$. Messengers of renal graft quality during warm and cold ischemia: a porcine microdialysis study. Transplant Proc 2013; 45(3): 1172-1177, https://doi.org/10.1016/j. transproceed.2012.10.014.
37. Amdisen C., Jespersen B., Møldrup U., Keller A.K. The unsuitability of implantable Doppler probes for the early detection of renal vascular complications - a porcine model for prevention of renal transplant loss. PLoS One 2017; 12(5): e0178301, https://doi.org/10.1371/journal.pone.0178301.

38. Fonouni H., Tahmasbi Rad M., Golriz M., Faridar A., Esmaeilzadeh M., Jarahian P., Hafezi M., Jafarieh S., MacherGoeppinger S., Longerich T., Orakcioglu B., Sakowitz O., Schmidt J., Mehrabi A. Using microdialysis for early detection of vascular thrombosis after kidney transplantation in an experimental porcine model. Nephrol Dial Transplant 2012; 27(2): 541-547, https://doi.org/10.1093/ndt/gfr308.

39. Fonouni H., Esmaeilzadeh M., Jarahian P., Rad M.T., Golriz M., Faridar A., Hafezi M., Jafarieh S., Kashfi A., Yazdi S.H., Soleimani M., Longerich T., Shevchenko M., Sakowitz O., Schmidt J., Mehrabi A. Early detection of metabolic changes using microdialysis during and after experimental kidney transplantation in a porcine model. Surg Innov 2011; 18(4): 321-328, https://doi. org/10.1177/1553350610392063.

40. Fonouni H., Jarahian P., Rad M.T., Golriz M., Faridar A., Esmaeilzadeh M., Hafezi M., Macher-Goeppinger S., Longerich T., Orakcioglu B., Sakowitz O.W., Garoussi C., Mehrabi A. Evaluating the effects of extended cold ischemia on interstitial metabolite in grafts in kidney transplantation using microdialysis. Langenbecks Arch Surg 2013; 398(1): 87-97, https://doi.org/10.1007/s00423-012-1010-0.

41. Fonouni H., Golriz M., Majlesara A., Faridar A., Esmaeilzadeh M., Jarahian P., Rad M.T., Hafezi M., Garoussi C., Macher-Goeppinger S., Longerich T., Orakcioglu B., Sakowitz O.W., Mehrabi A. Is microdialysis useful for early detection of acute rejection after kidney transplantation? Int J Surg 2015; 18: 88-94, https://doi.org/10.1016/j.jjsu.2015. 03.024 .

42. Hamaoui K., Gowers S., Damji S., Rogers M., Leong C.L., Hanna G., Darzi A., Boutelle M., Papalois V. Rapid sampling microdialysis as a novel tool for parenchyma assessment during static cold storage and hypothermic machine perfusion in a translational ex vivo porcine kidney model. J Surg Res 2016; 200(1): 332-345, https://doi. org/10.1016/j.jss.2015.07.004.

43. Khubutia M.Sh., Zhuravel S.V., Kozlov I.A., Romanov A.A., Goncharova I.I. Microdialysis - a new method of monitoring of the transplanted cadaveric kidneys function. Anesteziologiia i reanimatologiia 2015; 60(1): 69-72. 